\title{
Collaboration through Flickr \& Skype: Can Web 2.0 Technology Substitute the Traditional Design Studio in Higher Design Education?
}

\author{
Katja Fleischmann \\ James Cook University, Australia
}

\begin{abstract}
Technology has not only changed the work practice of designers but also how design is taught and learned. The emergence of digital technology has made computer labs a central learning space for design students. Since this change, studio-based learning in its traditional sense appears to be in decline in higher education institutions. This is in spite of the fact that characteristics of the studio have been identified as supporting interaction, active learning, and social engagement. These, however, are also characteristics connected to the use of Web 2.0 technologies such as Facebook, Flickr, and Skype. Could these services be utilized to revitalize studio culture in a contemporary sense? How can new technologies be used to facilitate interactions between students inherent to traditional studio culture? These questions were explored in practice by documenting student reactions to using Flickr and Skype during a five week project requiring collaboration between first year creative arts students at two geographically distant institutions in Australia. Findings provide a better understanding of how to expand the studio idea into the digital environment, in particular regarding the challenging task of offering the media design major fully online in the near future.
\end{abstract}

Keywords: Design education; Design studio; Web 2.0 technology; Social media; Higher education

\section{Introduction}

Technology has not only changed the work practice of designers but also how design is taught and learned. The emergence of digital technology has made computer labs a central learning space for design students. This is particularly the case in communication design, which comprises areas such as graphic design, digital design, media design, multimedia design, interaction design and visual communication (Design Council, 2005; Design Institute of Australia, 2009). A communication designer can engage in a variety of areas such as: 'identity design; editorial and book design; typography; information design; ... packaging; animation design; broadcast graphics and film titles; product, web and game interface design; interaction, environmental and exhibition graphics; data visualization; and any other activity of online and offline shaping of visual form' (Icograda, 2011, p. 8). Because of the wide range of activities that communication designers can engage in, curricula differ from one institution to another (Austerlitz et al., 2008). Nevertheless, undergraduate degree programs in communication design generally have some common characteristics, like applying similar learning and teaching strategies such as studio-based teaching and project-based learning (Davis, 2008; McCarthy \& Almeida, 2002). 
The characteristics of the studio, hence studio-based teaching in art, architecture and design, have been identified as supporting interaction, active learning and social engagement (e.g. STP, 2009). These, however, are also characteristics connected to the use of social media (such as Facebook and Flickr) in higher education learning environments. While design education 'is already often cited as the paradigm for new types of learning, because of its emphasis on open-ended, multi-disciplinary and problem-based learning; on open-plan and studio-based learning, built around collaborative critique and self-reflective iteration' (Boys, 2011, p. 8), the studio which facilitates these types of learning appears to be in decline (Ellmers, 2005; Morkel, 2011; STP, 2009). At same time, Web 2.0 technologies, in particular social media, promise to offer 'educators more ways to engage learners than any preceding educational technology' (LeNoue, Hall, \& Eighmy, 2011). Could Web 2.0 technologies, particularly social media, be utilized to revitalize studio culture in a contemporary sense?

\section{Characteristics and Qualities of the Design Studio}

A central pedagogy in design education is studio-based teaching (Sara, 2006; Shreeve, Wareing, \& Drew, 2008). Design learning in studios is often structured around projects where students respond to complex and open-ended assignments (Kuhn, 2001) with significant hands-on activities (McCarthy \& Almeida, 2002). Studio-based teaching and design learning is usually student-centered and built around 'dialogical learning and teaching' (Danvers, 2003, p. 51). This means that design learning is structured around an ongoing dialogue between students and educators, tutors, and support staff (Danvers, 2003; Shreeve, 2011). Studiobased learning uses the pedagogical concept of 'learning-by-doing' (Schön, 1983, 1987) and is grounded in Kolb's (1984) experiential learning model. The dialogue between students and educators, tutors, peers or visiting professionals is continued in 'critiques' in which finished work or works-in-progress are discussed in formal and informal ways (Kuhn, 2001; Wands, 2001).

Studio-based teaching, and hence the design studio as a higher education learning space, is seen as unique in that it is both a work space and a social environment (Hart, Zamenopoulos, \& Garner, 2011). According to Shreeve (2011), studio-based teaching supports the creation of a social space where students can develop peer learning and which is key to the development of a community of practice (Wenger, 1998). The community and social aspect of the design studio facilitate a sense of belonging that can motivate students to learn (Gee \& Miller, 2006; Sandbach, 2011). The design studio enables 'collective learning, interaction, passion and dedication for the discipline, nurturing independence of, and for, reflexive learning' (STP, 2009, p. 14). Yet the prevalence of the studio in design education itself is weakening (Ellmers, 2005; Morkel, 2011; STP, 2009). There are several reasons for this to occur. In communication design education, the computer lab has become central to design learning. The notion of providing each design student with a dedicated workspace in a studio, equipped with necessary hardware and software, is unsustainable in most institutions. Higher enrolment numbers and budget cuts have seen increasing pressure on resources for studio subjects, which are usually more expensive to teach than subjects in other disciplines (STP, 2009). Overall, studio-based teaching in a traditional design studio as a physical space is becoming much more difficult to sustain. 


\section{Social Media in Design Education}

Social media are 'a group of Internet-based applications that build on the ideological and technological foundations of Web 2.0, and that allow the creation and exchange of User Generated Content' (Kaplan \& Haenlein, 2010, p. 61). Social media 'have provided Internet users with the ability to easily create, contribute, communicate, and collaborate in the online environment without [the] need for specialized programming knowledge' (LeNoue, Hall, \& Eighmy, 2011, p. 5). There are a variety of types of social media: social networks like Facebook and Linkedln where users generate a profile and connect to other people; media sharing websites such as YouTube and Flickr, that allow users to upload and share media (e.g. pictures, videos); blogs (e.g. Wordpress) and microblogs (e.g. Twitter) that allow users to publish news; and socially curated sites such as Reddit, where users socially curate and promote news and stories (Grahl, 2012). Of these various types, social networking services such as Facebook (launched 2004), Linkedln (launched 2003) and also media sharing websites such as Flickr (launched 2004) have gained unprecedented user engagement; Facebook, for example, had 1.06 billion active monthly users in 2012 (Tam, 2013).

Recent studies propose the use of Web 2.0 technology, particularly social media, in the higher education context to support interaction, active learning, and social engagement. Social media in particular have the potential to enhance student success (Davis, Deil-Amen, Rios-Aguilar, \& Canche, 2012). Hunt, Huijser and Sankey (2011) suggest that there are parallels between what Barnes, Marateo and Ferris (2007) refer to as Net Generation students, who need interactivity, active engagement, social interaction and self-directed learning opportunities, and characteristics of Web 2.0 technologies such as social media. That is, social networking opportunities can create a connectedness and a sense of belonging (e.g. Davis, Deil-Amen, Rios-Aguilar, \& Canche, 2012; Hunt, Huijser, \& Sankey, 2011). 'Social media technology links people together in ways that resemble traditional feelings of connection, belonging, loosely defined memberships, exchange of feelings and ideas, and the reporting of experiences and actions' (Davis, Deil-Amen, Rios-Aguilar, \& Canches, 2012).

Research on the use of social media as a teaching and learning tool in design education is sparse. Some research places architectural design education on the forefront. Pak and Verbeke (2012), for example, suggest a 'Design Studio 2.0' that utilizes Web 2.0 technologies in a graduate urban architectural design studio, claiming 'that with the help of e-learning strategies, it is possible to support, augment and enrich the reflective communication between the design students and studio teachers' (p. 516). They see the potential in that students, while 'disconnected from the physical studio environment, ... can still learn from and comment on each others' projects and create a collective understanding of the design problem(s), the design context and the whole studio process' (Pak \& Verbeke, 2012, p. 504). Ham and Schnabel (2011) also argue that Web 2.0 social software can be used to extend conversations between students and educators on an additional platform.

Tate and Osborne (2013) have also recently conducted a study exploring 'whether or not Facebook could be used to increase the social interactions within an architectural studio', which revealed that in their case a 'sense of community was developed within the most successful online studio groups, with participation the key to the quality of social interaction in this medium.' Allen, Caple, Coleman and Nguyen (2012), who utilized Facebook as a social community space in classes in the School of Fine Arts and the Faculty of the Built Environment, reported an 'increased interaction between students and peers, students and lecturer, and students and tutors, which led to development of a learning community with shared 
resources.' Similar to findings in other disciplines, Ivalo and Gachago (2010, in Morkel, 2011) found that, in their architecture studio, the use of 'Facebook groups and blogs encourage[d] peer to peer support, collaborative learning, creation of student-generated content and improve interaction between staff and students, which are powerful indicators for student engagement.' Morkel (2011) equally found in her study that the 'online learning environment through Facebook does seem to provide a place for interaction, communication and dialogue.'

\section{Exploring the Effectiveness and Use of Social Media in an Undergraduate Media Design Context}

Utilizing the social media tools of the Learning Management System (LMS) Blackboard in the Media Design major of the Bachelor of New Media Arts degree in the School of Creative Arts at James Cook University is almost a 'tradition'. Since 2007 media design students are required to contribute to discussion boards and make use of other collaborative tools of the LMS (e.g. blogs, Blackboard groups) to communicate, share, and critique ideas online. Students upload links on Blackboard to media sharing services, such as YouTube, and can view or download lecture recordings (podcasts) they might have missed or want to review. Since more recently, media design students also learn how to build their virtual/digital identity and how to promote themselves in the digitally networked world by making use of social media tools such as the professional networking site Linkedln. Nevertheless an intentional use of social media as a teaching and learning strategy outside the university's LMS has not yet taken place. In order to develop a better understanding of how social media can be utilized in media design education, either as part of a blended delivery mode (face-to-face combined with online elements), or in preparation for the future delivery of the media design major fully online, a study in a first year media design subject was conducted.

\section{Project Design: The Design Studio Extended}

Living in the Tropics - Life in the City was a long distance collaborative visual communication design project between first year design students at the School of Creative Arts at James Cook University, located in North Queensland, and first year photography students at CATC Design School located in Melbourne (Figure 1). Students from both institutions were engaged in a five week collaborative project which utilized the photo sharing website Flickr and the voice-overIP communication service Skype as central technologies.

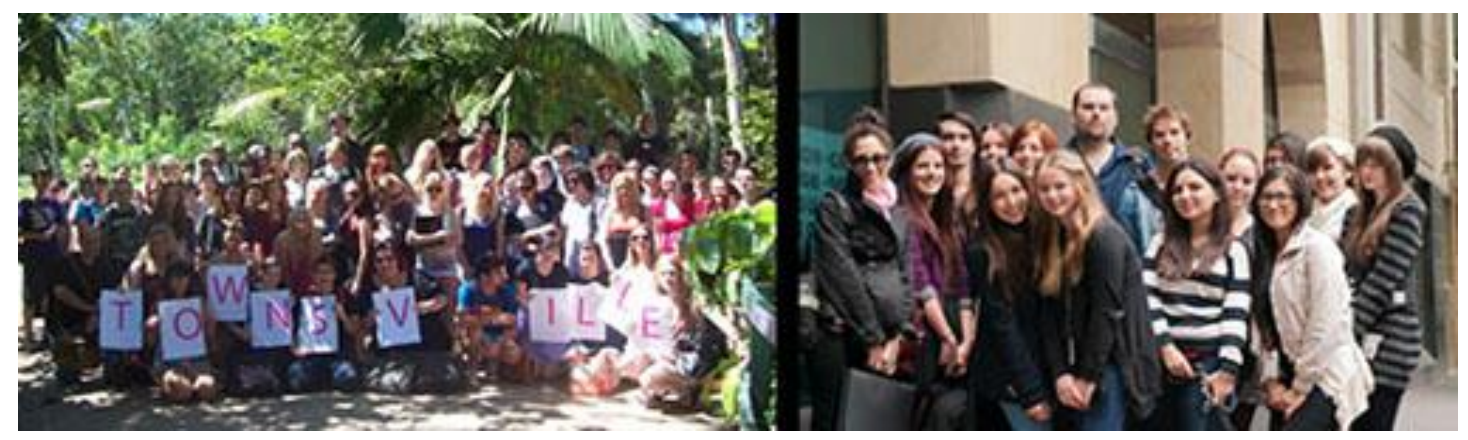

Figure 1. First Year Student Cohort at James Cook University, School of Creative Arts, Townsville and CATC Design School, Melbourne 


\section{Project Brief}

People are all exposed to a great deal of common visual information. Sources may include: television programs, magazines, books, outdoor advertising, and the Internet. However, differences still exist in the ways that we conceptualize and visualize different ideas dependent on our location and cultural context. In this exercise, students explored the differences in conceptualization and visual approaches taken to common themes, between those studying in the northern, regional tropics, and those studying in the urban, temperate south in Australia. Creative arts students studying in Melbourne (urban, temperate south) and in Townsville (regional, tropical north) were asked to make a series of images on nine different topics: Space, Place, Freedom, Fear, Opportunity, Culture, Fun, Sensation, and Me.

\section{Project Timeline}

In week one, students were introduced to the project both in Townsville and Melbourne respectively. Students had time to take pictures during the first two weeks (Figure 2, Figure 3) and outcomes were discussed within tutorial groups in each location. In week three, students uploaded their images to the Flickr folio 'Townsville images on nine visual themes' (http://www.flickr.com/groups/tvl9images) or 'Melbourne images on nine visual themes' (http://www.flickr.com/groups/mel9images) (Figure 4). Because of the large number of students in Townsville ( $n=142)$, media design students worked in twenty-three groups in Townsville, while students in Melbourne $(n=18)$ worked individually.

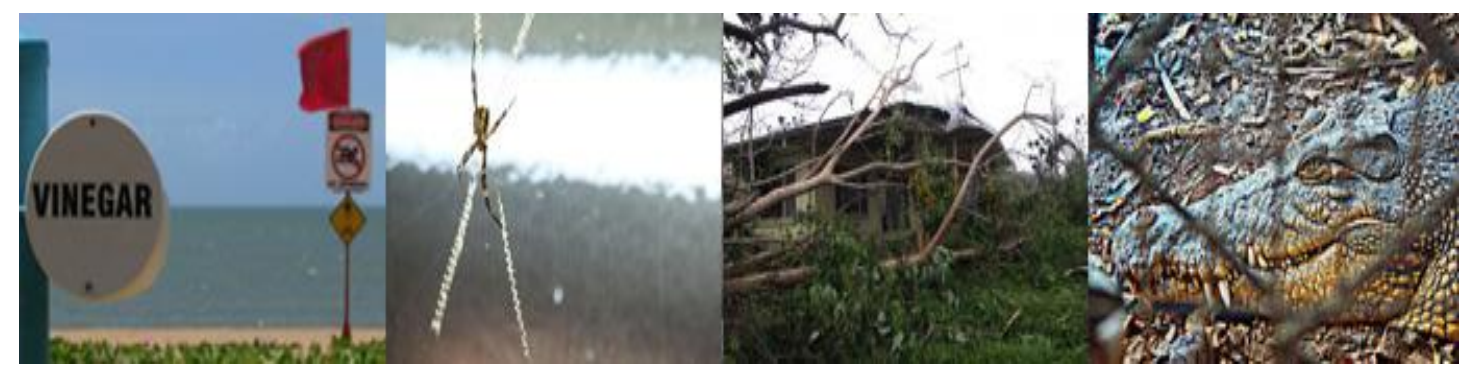

Figure 2. Topic 'Fear' - Townsville

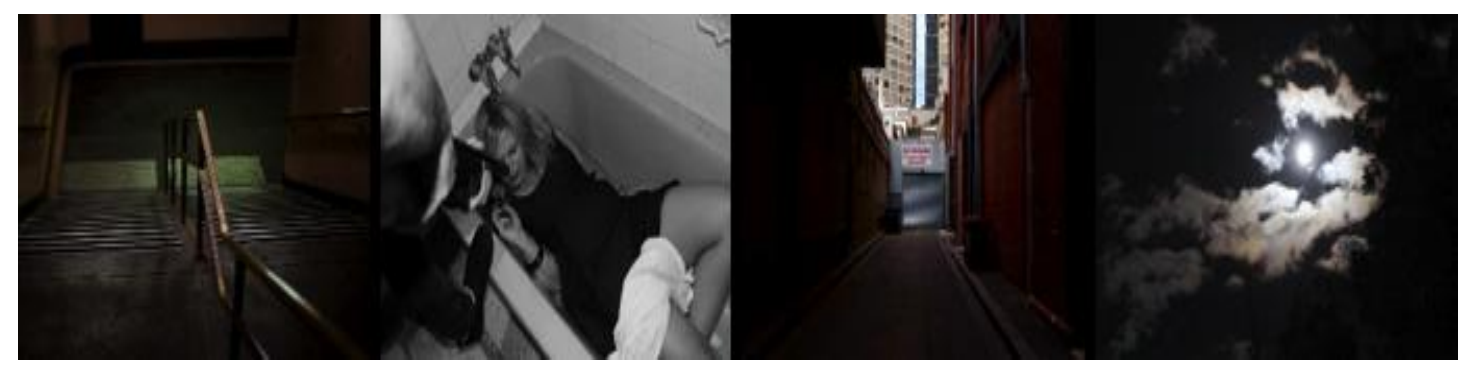

Figure 3. Topic 'Fear' - Melbourne 


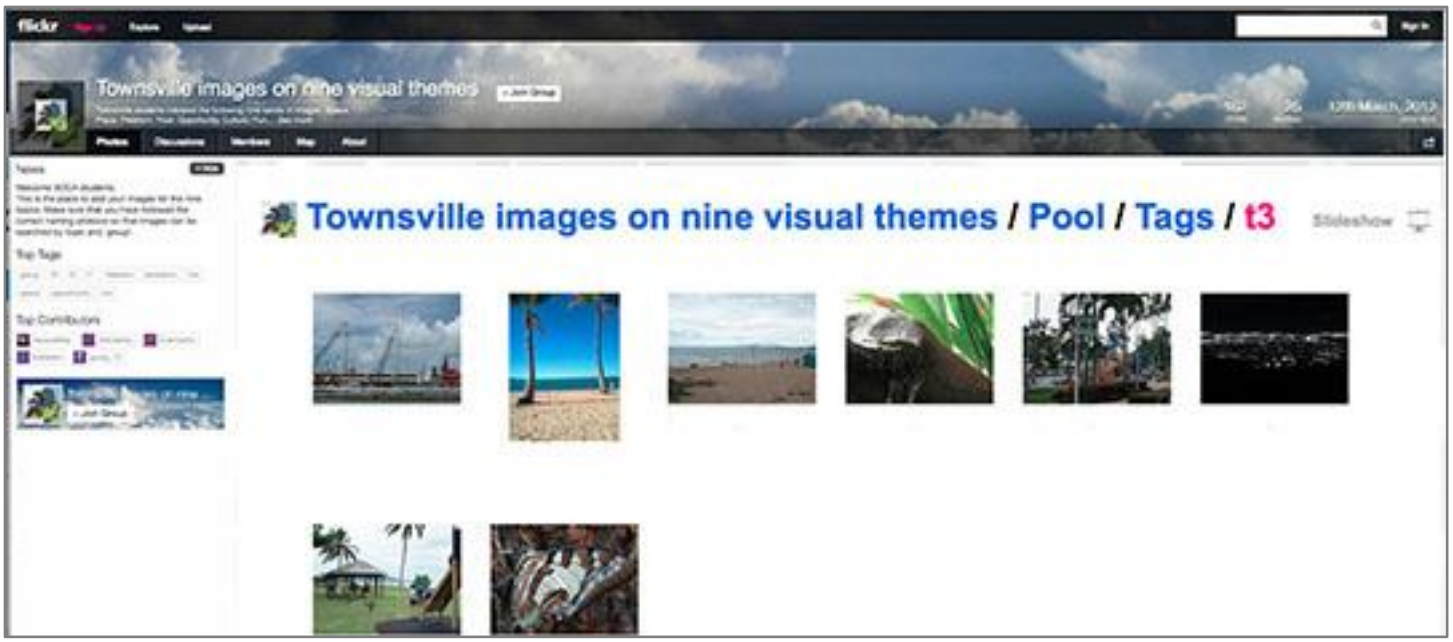

Figure 4. Flickr Uploaded Images, Townsville

Students in each location viewed the images on Flickr and discussed them in their tutorial groups. Students were then asked to reflect in writing on the differences between the Melbourne and Townsville images for each topic in regards to influences of location, environment and cultural context. In week four, Skype was used to engage both student groups into a face-to-face discussion and to share their observations. In this one hour session Townsville and Melbourne students discussed the differences in interpretation of each topic, contrasts therein, and, in particular, any surprises that they experienced between locations (Figure 5). Week five saw the submission of a journal from each student that included the nine images taken, the highest contrasting images from the other location, a summary of student beliefs concerning the influence of location and context on visual communication, and a short commentary on what students learned in group discussions and from the Skype session.

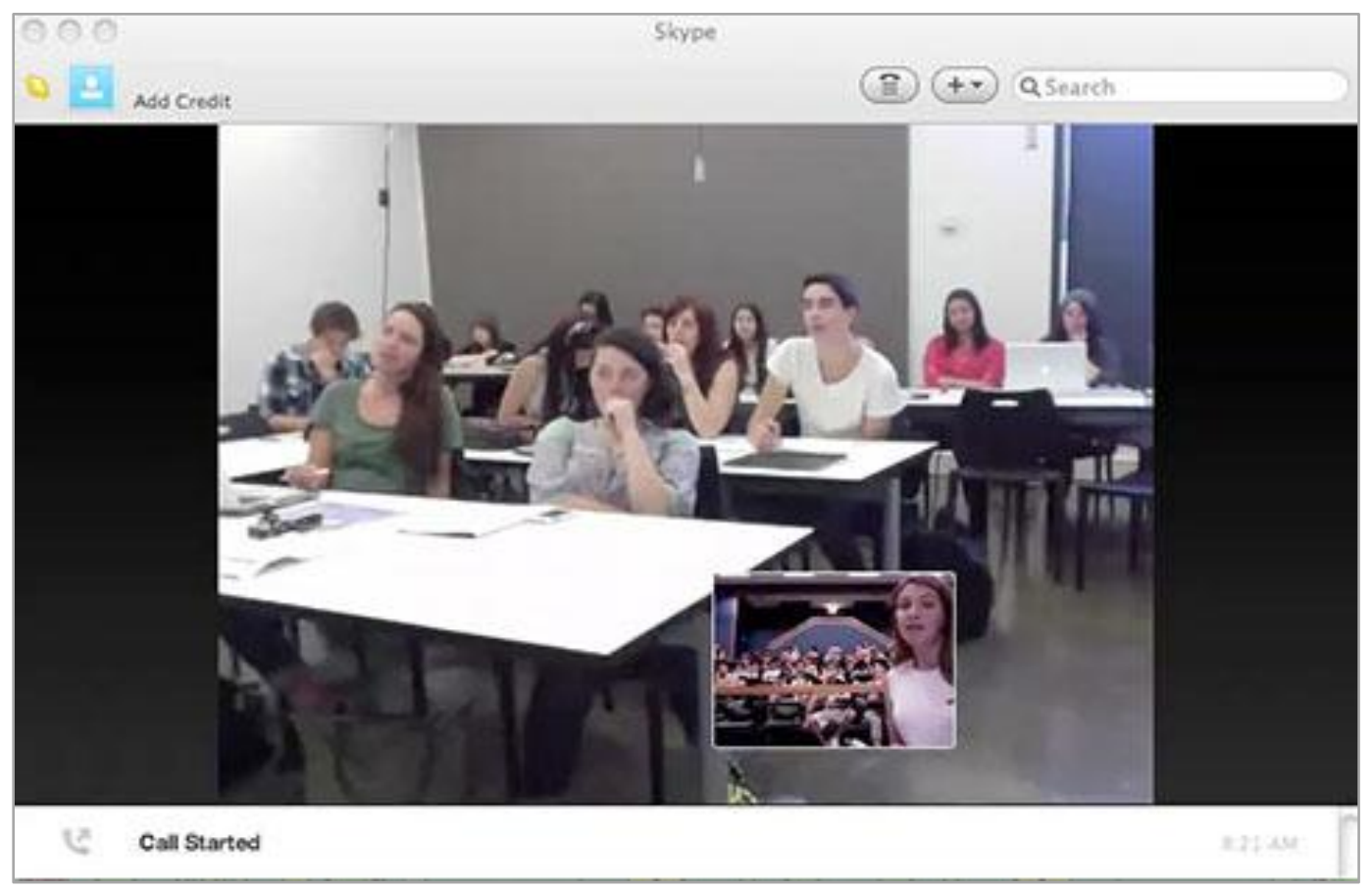

Figure 5. Skype Session between Students in Melbourne and Townsville 


\section{Methodology}

It was determined that this research study would be best framed by a pragmatic approach (Punch, 2009). The selection of an approach was directly linked to the purpose and the nature of the research questions asked (Armitage, 2007). The overarching research question (Could Web 2.0 technologies, particularly social media, be utilized to revitalize studio culture in a contemporary sense?) and sub-question (Can Web 2.0 technologies be used to facilitate interactions between students inherent to traditional studio culture?) were open and hence of exploratory nature. The questions were explored in practice by documenting student reactions to using Flickr and Skype during a five week project requiring collaboration between first year creative arts students at two geographically distant institutions in Australia.

\section{Research Design and Data Collection}

The mixing of qualitative and quantitative data hence a research design that best helps to answer the research questions was chosen (Johnson \& Christensen, 2008; Punch, 2009; Teddlie \& Tashakkori, 2009). Statistical forms of data and meaning-based data were mixed to illustrate or elaborate on an issue and/or to enhance understanding and present a more complete picture of the researched phenomenon (Fielding, 2012; Rossmann \& Wilson, 1995). The design for the qualitative part was interpretive qualitative research design because the researcher tried to understand participants' meaning making through an event or case (Altheide \& Johnson, 2011; Merriam, 1998).

When considering sampling strategies convenience sampling belonging to a non-probability sample design (Landreneau \& Creek, 2008) was considered as most appropriate in the case of exploring media design students' perspectives. When considering which methods of data collection (e.g. questionnaires, interviews) to apply, it was decided to obtain quantitative data through questionnaires and qualitative data through open-ended questions in questionnaires. The decision to use questionnaires for the collection of both data types (quantitative and qualitative data) at the same time was driven by the advantage of accessing large numbers of participants in a short timeframe. Questionnaires were also considered to be the most appropriate instrument to obtain an initial overview of a situation; for example students were asked a closed-ended question: Did you enjoy working with students from another region? (yes/no). Respondents were then asked for elaboration through open-ended questions: Why did you or why didn't you enjoy working with students from another region? Please explain. Therefore, questionnaires would not only return data on measurable indicators (e.g. How many students enjoyed the learning experience?) but would also provide deeper insight into the researched phenomena through collecting qualitative feedback through open-ended questions. According to Gray and Malins (2004), another advantage of using questionnaires is that the anonymity of respondents may also encourage greater honesty.

In order to explore the effectiveness of the use of social media in the media design subject, first year media design students $(n=142)$ were asked to participate in an online questionnaire that was designed and delivered using the online survey platform SurveyMonkey at the end of the project. Of the 142 first year media design students who participated in the long distance collaboration, 76 students responded in the online questionnaire, which is a response rate of $53.5 \%$. 


\section{Data Analysis}

SurveyMonkey automatically provided basic statistical data such as the tally of response totals, percentages, and response counts for quantitative data. Qualitative feedback from the online questionnaire was downloaded in pdf format and analyzed using the software NVivo-a qualitative data analysis program. In order to draw out essential characteristics of the qualitative data, NVivo was utilized to segment qualitative data and then coded through labels assigned to pieces of data (Punch, 2009). In the process, two types of coding (Punch, 2009) were applied: topic coding where the overarching theme was identified and analytic coding which looked at what was going on and what was said. Coding categories (topic coding) were not pre-established but left to emerge through grouping analytical coding units.

\section{Findings: Reflections of First Year Media Design Students}

Of the first year media design students in Townsville who responded, $87 \%$ of students (66) did enjoy the project and $13 \%$ (10) did not. The reason for this mostly positive feedback was identified by the majority of media design students (79\%, 60 students) as being the long distance exchange with students from Melbourne. For $20 \%$ of students (15), it did not make a difference that they worked with students from another region and one student (1\%) did not like the exchange. Nevertheless, $96 \%$ of students (73) agreed that they learned more about the relationship between words and images and the way we communicate visually by seeing and discussing the work of students from the other region using Flickr and Skype. Table 1 overviews the quantitative data.

Table 1. Quantitative Feedback from First Year Media Design Students $(n=76)$

This semester you worked on a project that focused on differences that might exist in the way that we visually interpret words based on location. Did you enjoy working on this project?

\begin{tabular}{|c|c|c|c|}
\hline & Yes & No & \\
\hline$\%$ & 87 & 13 & \\
\hline Number of media design students & 66 & 10 & \\
\hline \multicolumn{4}{|c|}{ Did you enjoy working with students from another region? } \\
\hline & Yes & No & $\begin{array}{l}\text { It did not make } \\
\text { a difference }\end{array}$ \\
\hline$\%$ & 79 & 1 & 20 \\
\hline Number of media design students & 60 & 1 & 15 \\
\hline
\end{tabular}

Do you think that you have learned more about the relationship between words and images and the way that we communicate visually by seeing the work of students from the other region?

\begin{tabular}{lll}
\hline & Yes & No \\
\hline$\%$ & 96 & 4 \\
Number of media design students & 73 & 3 \\
\hline \hline
\end{tabular}

From the qualitative feedback provided by media design students, general trends could be identified. Each trend is illustrated with a typical comment from students. Media design 
students stated that sharing images on Flickr and discussing these in groups enabled them to:

- see and experience the contrast between and distinctiveness of the work from students from these two locations first hand.

"It was mind blowing to see how differently they interpreted some of the topics compared to us."

- develop understanding for other people/user groups.

"That even if you are the same gender and age group, two different people can read a word and think different things."

- $\quad$ see the world from another person's perspective.

"It was very interesting to compare the thinking process of people in these two locations, to see just how different the train of thought can be just by changing locations."

Furthermore, media design students stated that, in addition to becoming more proficient in image editing and graphic software, some students learned to work with Flickr as an outcome of this class. It was interesting that several students did not know how to use Flickr prior to participating in this subject. Overall, there were a wide range of additional learning outcomes achieved through this five week project which are best illustrated by the typical comments from media design students below:

- "I have learnt that there are many possibilities to word meanings if you travel to more than one place."

- "I have learnt that you must be incredibly considerate when it comes to designing anything as someone from a different background, with different influences in their lives can interpret images and words in different ways."

- "I have learned a lot about design principles, color, typography and layouts.... have also increased my knowledge on presentation and professionalism taking a step from high school project to university level."

\section{Discussion and Conclusion}

Although this is a small-scale study, the findings provide some insight as to if and how social media can be effectively used as an extension of face-to-face teaching in design education in a higher education context. Using Web 2.0 technology as educational technology for teaching this five week project has proven successful in creating an engaging learning activity for students as suggested by LeNoue, Hall, and Eighmy (2011). Feedback from the media design students suggests that the intended learning outcomes of this project have been achieved. This is despite, or better because, of students being in different locations.

In the first year media design subject, Flickr and Skype were used to facilitate communication and exchange between students in geographically different locations. Web 2.0 technology was used to bridge the distance and facilitate exchange, communication, and collaboration in the virtual environment. It is clear that certain learning outcomes in this first year media design subject could not have been achieved without the use of Flickr and Skype as tools for exchange and communication across the distant locations within the given timeframe. Connecting these 
two classes, one located in the urban, temperate south, and the other in the regional, tropical north, was easy for educators to set up and manage. To achieve similar learning outcomes-a first-hand experience of a place with a different social, cultural and natural environment that enables students to experience contrast and identify the distinctiveness of their own habitatwould require students and educators to travel. This is resource-intense in terms of time and money for all involved.

Although the project would have not been possible without using Flickr and Skype, technology was secondary to the content taught and learning outcomes to be achieved. The time 'to deal with technology' (set up, troubleshoot) was minimal from the educators' side. Students engaged easily with Flickr and overall working with Flickr was without problems for students. Therefore, technology, in this particular case Flickr and Skype, was not considered a stumbling block or barrier to learning as this has been identified in some earlier studies that engaged students in digitally mediated design education (e.g. Bennett, 2009; Hart, Zamenopoulos, \& Garner, 2011). Web 2.0 technology was used as a tool to successfully facilitate and enable the learning outcomes.

Social media can enable a culture of sharing and increased interaction between students as discussed by Allen, Caple, Coleman, and Nguyen (2012), Davis, Deil-Amen, Rios-Aguilar, and Canche (2012), Morkel (2011) and Tate and Osborne (2013) which is indeed similar to the traditional studio culture, in which the face-to-face dialogue among students and between students and educators facilitates the sharing and discussing of ideas and the subsequent peer learning (e.g. Shreeve, 2011; STP, 2009). This process is deeply embedded in and an inherent part of design learning. Findings from this research study suggest that peer learning took place through ongoing communication, interaction and exchange between members of a group, between groups ( 23 groups in Townsville) and finally between students in the two different locations. Flickr and Skype supported social learning in this project as discussed for example by Davis, Deil-Amen, Rios-Aguilar, and Canche (2012) in that the 'understanding of content [was] socially constructed through conversations about that content and through grounded interactions around problems or actions' (Brown, 2008, p. xii). The five week project was intended to initiate conversations and discussions. Using Flickr enabled students to engage in an ongoing dialogue and Skype allowed to continue that dialogue in a more direct fashion. Overall, the interaction between students facilitated through Web 2.0 technology can be seen as supporting the creation of a learning culture based on dialogical learning (Danvers, 2003), which is a cornerstone of the traditional design studio.

While Skype required students in both locations to be present in the classroom in order to interact in real time (synchronous activity), the use of Flickr enabled students to continue their discussion and exchange outside assigned tutorial times (asynchronous activity). Although not part of this study, future research could explore the extent to which students take advantage of this opportunity. Overall, using Web 2.0 technology as educational technology in design education can be recommended as an extension of the traditional design studio. As Pak and Verbeke (2012) argue that e-learning strategies which involve Web 2.0 technology support reflective communication between design students and students and educators in architecture design education, this study confirms their view in regards to supporting and enabling communication and exchange between students. However, in order to explore to what extent Web 2.0 technology and in particular social media can completely substitute face-to-face design education further research needs to be undertaken. Certainly, longer, more in-depth studies are needed particularly studies that focus on exploring the effectiveness of Web 2.0 technology in a design degree that is delivered fully online. 
The combination of engaging students in asynchronous activities (Flickr) and synchronous activities (Skype) as well as the combination of face-to-face and virtual dialogue during the five week project is seen as significant factor for the success of this project and students achieving intended learning outcomes. Whether such project or design education in general can be effective when teaching and learning is based only on asynchronous activities needs to be explored. Furthermore, this study focused on the effectiveness of Flickr and Skype as extension of a traditional design learning environment. More research is needed to explore the effectiveness of other social media tools such as Facebook. However, in the first year media design subject Flickr and Skype provided a viable opportunity to recreate features of the traditional design studio in the virtual environment. Flickr and Skype have emerged in this study as useful tools in creating dialogue and exchange. Such learning activity involving Web 2.0 technology can be recommended for extending the traditional design studio and offering the media design degree in a blended delivery mode in the future.

\section{Acknowledgement}

The author would like to acknowledge the contribution of Clive Hutchison, Head of Photography at CATC Design School, who taught, organized and ran this project on the Melbourne side.

\section{References}

Allen, B., Caple, H., Coleman, K., \& Nguyen, T. (2012, November). Creativity in practice: Social media in higher education. Paper presented at ASCILITE: Future challenges-Sustainable futures. Wellington, New Zealand.

Altheide, D. L., \& Johnson, J. M. (2011). Reflections on interpretive adequacy in qualitative research. In N. K. Denzin \& Y. S. Lincoln (Eds.), The Sage handbook of qualitative research (pp. 581-594). California: Thousand Oaks.

Armitage, A. (2007, September). Mutual research designs: Redefining mixed methods research design. Paper presented at the British Educational Research Association Annual Conference. University of London.

Austerlitz, N., Blythman, M., Grove-White, A., Jones, B. A., Jones, C. A., Morgan, S., Vaughan, S. (2008). Mind the gap: expectations, ambiguity and pedagogy within art and design higher education. In L. Drew (Ed.), The student experience in art and design higher education: Drivers for change (pp. 125-148). Cambridge: Jill Rogers Associates.

Barnes, K., Marateo, R.C., \& Ferris, S.P. (2007). Teaching and learning with the net generation. Innovate, 3(4), 771-772.

Bennett, R. (2009). Drawing on the virtual collective: exploring online collaborative creativity (PhD), University of Sydney. Retrieved on 15 February 2010 from http://ses.library.usyd. edu.au/handle/2123/6433

Boys, J. (2011). Towards creative learning spaces: Re-thinking the architecture of postcompulsory education. New York: Routledge.

Brown, J.S. (2008). Foreword: Creating a culture of learning. In T. Liyoshi \& M.S.V. Kumar (Eds.), Opening up education: The collective advancement of education through open technology, open content, and open knowledge (pp. xi-xvii). Cambridge: The MIT Press. 
Danvers, J. (2003). Towards a radical pedagogy: Provisional notes on learning and teaching in art \& design. International Journal of Art and Design Education, 22(1), 47-57.

Davis, M. (2008, April). Toto, I've got a feeling we're not in Kansas anymore.... Paper presented at the AIGA Conference. Boston.

Davis, C. H. F. I., Deil-Amen, R., Rios-Aguilar, C., \& Canche, M. S. G. (2012). Social media in higher education: A literature review and research directions. The Center for the Study of Higher Education at the University of Arizona and Claremont Graduate University.

Design Council. (2005). The business of design. Retrieved on 15 July 2007 from http://www.designcouncil.org. uk/publications/the-business-of-design/

Design Institute of Australia. (2009). Structure of the design industry: A structural view of design disciplines. Retrieved on 20 August 2009 from http://www.dia.org.au

Ellmers, G. (2005, September). A re-examination of graphic design pedagogy, and its application at the University of Wollongong: Towards a PhD study in design education. Paper presented at ACUADS Conference. Edith Cowan University, Perth.

Fielding, N. G. (2012). Triangulation and mixed methods designs: Data integration with new research technologies. Journal of Mixed Methods Research, 6(2), 124-136.

Gee, L. \& Miller, H. (2006). Human-centered design guidelines. In D. G. Oblinger (Ed.), Learning spaces (pp. 10.11-10.13): EDUCAUSE. Retrieved on 13 August 2013 from http://www. educase.edu/research-and-publications/books/learning-spaces

Grahl, T. (2012). The 6 types of social media. Retrieved on 20 June 2013 from http://outthinkgroup.com/tips/the-6-types-of-social-media

Gray, C. \& Malins, J. (2004). Visualizing research: A guide to the research process in art and design. Burlington: Ashgate.

Ham, J. J. \& Schnabel, M. A. (2011). Web 2.0 virtual design studio: Social networking as facilitator of design education. Architectural Science Review, 54(2), 108-116.

Hart, J., Zamenopoulos, T. \& Garner, S. (2011). The learning scape of a virtual design atelier. Compass: The Journal of Learning and Teaching at the University of Greenwich, 3, 1-15.

Hunt, L., Huijser, H., \& Sankey, M. (2011). Learning Spaces for the digital Age: Blending space with pedagogy. In M. Keppell, K. Souter \& M. Riddle (Eds.), Physical and virtual learning spaces in higher education: Concepts for the modern learning environment (pp.182-195). Heshey, Pennsylvania: IGI Global.

Icograda (International Council of Graphic Design Associations). (2011, October). ICOGRADA design education manifesto. Tapei. Retrieved on 3 January 2012 from http://www. icograda.org/education/ manifesto.htm

Johnson, B. \& Christensen, L. (2008). Educational research - Quantitative, qualitative, and mixed approaches (3rd ed.). Los Angeles: Sage.

Kaplan, A. M. \& Haenlein, M. (2010). Users of the world, unite! The challenges and opportunities of social media. Business Horizons, 53, 59-63.

Kolb, D. A. (1984). Experiential learning: Experience as the source of learning and development. New Jersey: Prentice-Hall.

Kuhn, S. (2001). Learning from the architecture studio: Implications for project-based pedagogy. International Journal of Engineering Education, 17(4-5), 349-352. 
Landreneau, K. J. \& Creek, W. (2008). Sampling strategies. Retrieved on 12 August 2009 from www.natco1.org/research/files/SamplingStrategies.pdf

LeNoue, M., Hall, T., \& Eighmy, M. A. (2011). Adult education and the social media revolution. Adult Learning, 22(4), 4-11.

McCarthy, S. \& Almeida, C. M. d. (2002). Self-authored graphic design: A strategy for integrative studies. Journal of Aesthetic Education, 36(3), 103-116.

Merriam, S. B. (Ed.). (1998). Qualitative research in practice: Examples for discussion and analysis. San Fransisco, CA: Jossey-Bass.

Morkel, J. (2011, September). Facebook-enhanced face to face learning: The architecture studio. Paper presented at the 5th International Computer \& Instructional Technologies Symposium. Fırat University, Elazığ, Turkey.

Pak, B. \& Verbeke, J. (2012). Design Studio 2.0: Augmenting reflective architectural design learning. Journal of Information Technology in Construction (ITcon), 17, 502-519. Retrieved on 13 April 2013 from http://www.itcon.org/cgi-bin/works/Show?2012_32

Punch, K. (2009). Introduction to research methods in education. London: Sage.

Rossman, G. B. \& Wilson, B. L. (1985). Numbers and words: Combining quantitative and qualitative methods in a single large-scale evaluation study. Evaluation Review, 9(5), 627-643.

Sandbach, K. (2011). Graphic design and the aesthetics of place. Iridescent-Icograda Journal of Design Research, 1(2), 148-159. Retrieved on 12 October 2012 from http://iridescent. icograda.org/2011/05/03/graphic_design_and_the_aesthetics_of_place.php

Sara, R. (2006, April). Sharing and developing studio practice: A cross-disciplinary study comparing teaching and learning approaches in the art and design disciplines. Paper presented at the CLTAD Conference. London.

Schön, D. (1983). The reflective practitioner: How professionals think in action. New York: Basic Books.

Schön, D. (1987). Educating the reflective practitioner. San Francisco: Jossey-Bass.

Shreeve, A. (2011, May). The way we were? Signature pedagogies under threat. Researching Design Education. Paper presented at the 1st International Symposium for Design Education Researchers. Paris: Cumulus Association.

Shreeve, A., Wareing, S., \& Drew, L. (2008). Key aspects of teaching and learning in the visual arts. In H. Fry, S. Ketteridge, \& S. Marshall (Eds.), A handbook for learning and teaching in higher education: Enhancing academic practice (pp.345-362). London: Routledge.

STP (Studio Teaching Project). (2009). Curriculum development in studio teaching: Volume one: STP final report. Retrieved on 10 December 2010 from http://www.studioteaching.org/ ?page=key_findings

Tam, D. (2013). Facebook by the numbers: 1.06 billion monthly active users. CNET. Retrieved on 25 March 2013 from http://news.cnet.com/8301-1023_3-57566550-93/facebook-bythe-numbers-1.06-billion-monthly-active-users/

Tashakkori, A. \& Teddlie, C. (2009). Integrating qualitative and quantitative approaches to research. In L. Bickman \& D. J. Rog (Eds.), The SAGE handbook of applied social research methods (pp.283-317). Los Angeles: Sage. 
Tate, D. \& Osborne, L. (2013). Facebook: A 24 hour studio environment for contemporary architectural education. Retrieved on 13 April 2013 from http://eprints.qut.edu.au/ 59549/

Wands, B. (2001). A philosophical approach and educational options for the e-designer. In S. Heller (Ed.), The education of an e-designer (pp.20-23). New York: Allworth.

Wenger, E. (1998). Communities of practice: Learning, meaning, and identity. Cambridge: Cambridge University Press.

Correspondence: Katja Fleischmann, Senior Lecturer and Design Researcher, School of Creative Arts, James Cook University, Townsville, Australia 